\title{
Revista \\ REFLEXÃo Brasileira de Enfermagem REBEn \\ Ações de enfermagem em nefrologia: um referencial expandido além da concepção biologicista de saúde
}

\author{
Nursing actions in nephrology: \\ a theoretical referral expanded beyond the biologicist health conception \\ Acciones de enfermería en nefrología: \\ un referencial teorico difundido además de la concepción biologicista de salud
}

Mercedes Trentini

Enfermeria. Doutora em Enfermagem. Professora da UFSC/PUC-PR. mertini@terra.com.br

Márcia Regina Cubas

Enfermeira. Mestre em Saúde Pública. Doutoranda em Enfermagem na EEUSP. Professora da PUC-PR.

Conteúdo apresentado em forma de conferência no XII Congresso Brasileiro de Enfermagem em Nefrologia

\section{RESUMO}

Este artigo focaliza modos de atuação da enfermagem em nefrologia nos programas de promoção de saúde. Para tanto, apresentamos um referencial teórico formado pelos conceitos de promoção da saúde, educação em saúde e tecnologias. A concepção de promoção da saúde está ancorada nos documentos da Primeira Conferência Internacional sobre o tema, realizada em Ottawa, Canadá em 1986. A educação em saúde está alicerçada no paradigma do "empowerment", visto como um processo de ação social que promove participação das pessoas no controle sobre suas vidas e saúde. O conceito de tecnologias está apresentado de acordo com a concepção de Merhy, que as classifica em tecnologias duras, leve-duras e leves. Este referencial, certamente, representará um novo desafio para enfermeiras/enfermeiros de nefrologia.

Descritores: Enfermagem; Nefrologia; Promoção da Saúde.

\section{ABSTRACT}

This article focuses ways of nursing performance in nephrology in the health promotion programs. Therefore, we present a theoretical referral formed by concepts of health promotion, health education and technologies. The conception of health promotion is anchored in the First International Conference documents about the subject, which took place in Ottawa, Canada in 1986. Health education is based on the empowerment paradigm, seen as a social action process that promotes people's participation in controlling their lives and health. The concept of technologies is presented in accordance with Merhy's conception, classifying them as hard technologies, lighthard and light ones. This referral will surely represent a new challenge for nurses in nephrology. Descriptors: Nursing; Nephrology; Health Promotion.

\section{RESUMEN}

Enfoca modos de actuación de la enfermería en nefrología en los proyectos de promoción de salud. Presentamos un referencial formado por los conceptos de promoción de la salud, educación en salud y tecnologías. La concepción de promoción está apoyada en la Carta de Ottawa, 1986. la educación en salud está basada en el paradigma del "empowerment", visto como un proceso de acción social que promoví participación de las personas en el control sobre sus vidas. El concepto de tecnologías está presentado en conformidad con la concepción de Merhy que las clasifica en tecnologías "duras, livianas-duras y livianas". Este referencial, representará un nuevo desafío para la enfermería de nefrología.

Descriptores: Enfermería; Nefrología; Promoción de la Salud.

Trentini M, Cubas MR. Ações de enfermagem em nefrologia: um referencial teórico expandido além da concepção biologicista de saúde. Rev Bras Enferm 2005 jul-ago; 58(4):481-5.

\section{INTRODUÇÃO}

O conceito de enfermagem, em nefrologia, geralmente representa o cuidado paliativo, mediado com tecnologias duras de última geração, e desenvolvido dentro de unidades de diálise/hemodiálise com pessoas no estágio final da insuficiência renal crônica. Compartilhando idéias com uma enfermeira da área, manifestou-se a preocupação com o cuidado de enfermagem na nefrologia e pensou que deveria estendê-lo para além do suporte ao cliente na fase final da insuficiência renal crônica, incluindo a prevenção. Esta necessidade de atuação não se restringe apenas a uma intenção individual, mas se trata de uma visão coletiva, tendo em vista que este tema foi alocado no XII Congresso Brasileiro de Enfermagem em Nefrologia.

Neste artigo, propomos responder à seguinte questão: de que maneira a enfermagem de nefrologia poderá atuar nos programas de promoção da saúde?

Nas últimas décadas, o Diabetes Mellitus do tipo 2 tem aumentado de modo significativo na população brasileira: em 1990, representava 7,6\% da população geral, e a previsão é que, em 
2025, atinja um percentual de $27 \%$. A doença está estreitamente associada à insuficiência renal crônica, pois sua complicação mais comum é a nefropatia diabética ${ }^{(1)}$.

Há três fases da prevenção da nefropatia diabética ${ }^{(1)}$ : a da instalação da patologia; a da passagem da micro para macroalbuminúria; e a da instalação da uremia. De modo genérico, é classificada em dois grupos: causada por fatores genéticos e não genéticos. 0 enfoque neste artigo será nos fatores não genéticos, considerando que estes podem ser modificados e também por requererem ações de enfermagem preventiva.

\section{TENDÊNCIAS}

No intuito de tornar mais compreensível o paradigma atual relacionado às ações de saúde, mostraremos sucintamente a evolução histórica das quatro principais tendências da epidemiologia a partir dos meados do século XIX.

A Tendência Ambiental, denominada Era da Estatística Sanitária, foi baseada na teoria miasmática e era dominante nos meados do século $X I X^{(2)}$. Sua gênese remonta à Idade Média, pela preocupação com as doenças infecciosas e as grandes epidemias que assolavam a Europa. Argumentava que a morbidade e a mortalidade eram originadas pelo envenenamento inalado do meio ambiente - os humores e as ações preventivas e terapêuticas consistiam nas medidas higienistas ${ }^{(3)}$. A teoria sustentava que esta ação higienista dispersava o miasma e reduzia a morbidade e a mortalidade, o que, de fato, ocorreu. Acreditava também que eliminava a pobreza de novos moradores nas áreas tratadas, o que não aconteceu(2) $^{(2)}$

A Tendência Biologicista nasceu ainda no século XIX, sustentada pelo paradigma da "caixa preta" das doenças infecciosas - a teoria dos germes, defendendo a hipótese de que a maior causa das doenças era por infecção de microorganismos. Teve alcance com a revolução pasteuriana, que pautou todo seu conhecimento científico no positivismo, negando qualquer outra explicação para o surgimento da doença, além da bacteriológica. Foi sustentada pelas pesquisas de laboratório, mostrando a cultura de material colhido de pessoas infectadas, a reprodução e transmissão em laboratório. portanto, a prevenção passou a incluir vacinoterapia, soroterapia, antimicrobianos químicos e os antibióticos, que produziram grandes impactos na história da medicina ${ }^{(3)}$.

Nesta época, em que se encontrava a hegemonia da unicausalidade, é que se insere a enfermagem moderna com Florence Nightingale, cuja visão do processo saúde-doença e da enfermagem embasava-se num mesclado de várias teorias, possibilitando a construção da enfermagem com vistas à manutenção de ótimas condições para a recuperação da saúde enfatizando a atenção individual, porém não descartando o estudo das condições do coletivo e do ambiente em que ele se insere ${ }^{(4)}$.

No paradigma da "caixa preta" os problemas de saúde são vistos somente na dimensão individual e biológica. A prevenção de doenças consiste no controle dos fatores de risco pela modificação do estilo de vida, porém, o conhecimento dos fatores e as intervenções direcionadas às mudanças de comportamento individual têm se mostrado insuficiente. Este paradigma, sozinho, não elucida forças sociais em relação à saúde, pois mesmo quando a intenção é atingir o coletivo, o foco é sempre direcionado para o indivíduo(3)

A Tendência Ecológica, representada pela teoria da metáfora da "caixa chinesa", nasceu da crítica ao modelo biologicista, com a argumentação de que um foco exclusivo nos fatores de risco em nível individual não convencia os cientistas. Propunha lidar igualmente com as causas patológicas em nível da sociedade, e com as patogêneses e causalidade em nível biológico (molecular) ${ }^{(2)}$, defendendo a idéia de que a interação do agente com o hospedeiro ocorre num contexto composto de elementos físicos, biológicos e sociais.

Esta visão introduziu uma visão de multicausalidade das doenças ${ }^{(5)}$. Concebe saúde como um estado de equilíbrio entre o indivíduo e 0 ambiente; desta forma, admite interpretações plurais que podem ser incorporadas ao ambiente natural ou social indo além da visão puramente individual; no entanto, conservou a determinação biológica pelo equilíbrio(6). A ecologia humana vê as pessoas como sistemas abertos em contínua interação com o ambiente e enfatiza a inseparabilidade de fatores ambientais internos e externos ao indivíduo na tentativa de manter equilíbrio e, simultaneamente, maximizar os esforços e recursos das pessoas ${ }^{(7)}$. A principal contribuição da ecologia como modelo conceitual que tem aplicabilidade para a prática de enfermagem, consiste na ênfase centrada na relação do homem com o ambiente, dando particular atenção às junturas e nos pontos nos quais os indivíduos se deparam e respondem ao ambiente. Enquanto o modelo ecológico oportunizou a criação de conceitos relevantes para a epidemiologia, por outro lado, a multiplicação de estudos relacionados às doenças crônicas degenerativas agregou o modelo de "fator de risco" ao paradigma ecológico original. Desse modo, o ecológico multicausal é disfarçado em um novo tipo de unicausalismo e, assim, o fenômeno particular deixou de ser observado na sua integralidade, passando a ser visto como parte isolada ${ }^{(5)}$.

A Tendência Social, conhecida como "Epidemiologia Social/Crítica" aparece como novo paradigma num momento de crise econômica e social, juntamente com repressões de ordem político-ideológica, principalmente na América Latina ${ }^{(5)}$. Na década de 70 o movimento da Reforma Sanitária no Brasil foi apoiado por este referencial, defendido por um grande contingente de produção científica questionando a concepção de saúde limitada à dimensão biológica individual(8). Esta tendência considera a visão biológica e ecológica da saúde-doença, mas vai além: "adquire uma nova dimensão que incorpora uma nova visão totalizadora da saúde, como questão social, fixando assim um marco adequado para a investigação de seus problemas particulares"(6). A tendência social assumiu a seguinte definição de saúde: A existência de saúde, (...) é produzida dentro de sociedades que, além da produção, possuem formas de organização da vida cotidiana, da sociabilidade, da afetividade, da sensualidade, da subjetividade, da cultura e do lazer, das relações com o meio ambiente. É antes resultante do conjunto da experiência social, individualizada em cada sentir e vivenciada num corpo que é também, não esqueçamos, o biológico. Uma concepção de saúde não-reducionista deveria recuperar o significado do indivíduo em sua singularidade e subjetividade na relação com os outros e com o mundo. Pensar a saúde hoje passa então por pensar o indivíduo em sua organização da vida cotidiana, tal como esta se expressa não só através do trabalho, mas também do lazer- ou da sua ausência, por exemplo do afeto, da sexualidade, das relações com o meio ambiente." (...)(9).

\section{REFERENCIAL TEÓRICO PARA AÇÕES DE SAÚDE NAS CONDIÇÕES CRÔNICAS}

Diante de uma visão tão ampla de saúde, é evidente que necessitamos de um suporte teórico congruente com esta amplitude, a fim de apoiar nossas ações de saúde na área das condições crônicas e especificamente na nefropatia. Retomando a questão do início deste artigo: "de que maneira a enfermagem de nefrologia poderá atuar nos programas de promoção da saúde?" apresentamos um referencial teórico, (esquematizado na Figura 1) que acreditamos ser apropriado para a melhoria da saúde dos grupos vulneráveis à Nefropatia Diabética e, portanto, capaz de produzir impacto na prevenção de seus determinantes.

A promoção da saúde pode ser agrupada em três modelos genéricos concebidos ao longo da história: o modelo médico biologicista; o psicoeducacional e o do "empowerment". Os dois primeiros têm alguns conteúdos em comum e formam o modelo tradicional. O modelo médico biologicista tem por meta a mudança de comportamento dos usuários, e demanda informação e orientação para a mudança de crenças e as condutas referentes aos fatores de risco, enquanto o psico-educacional 


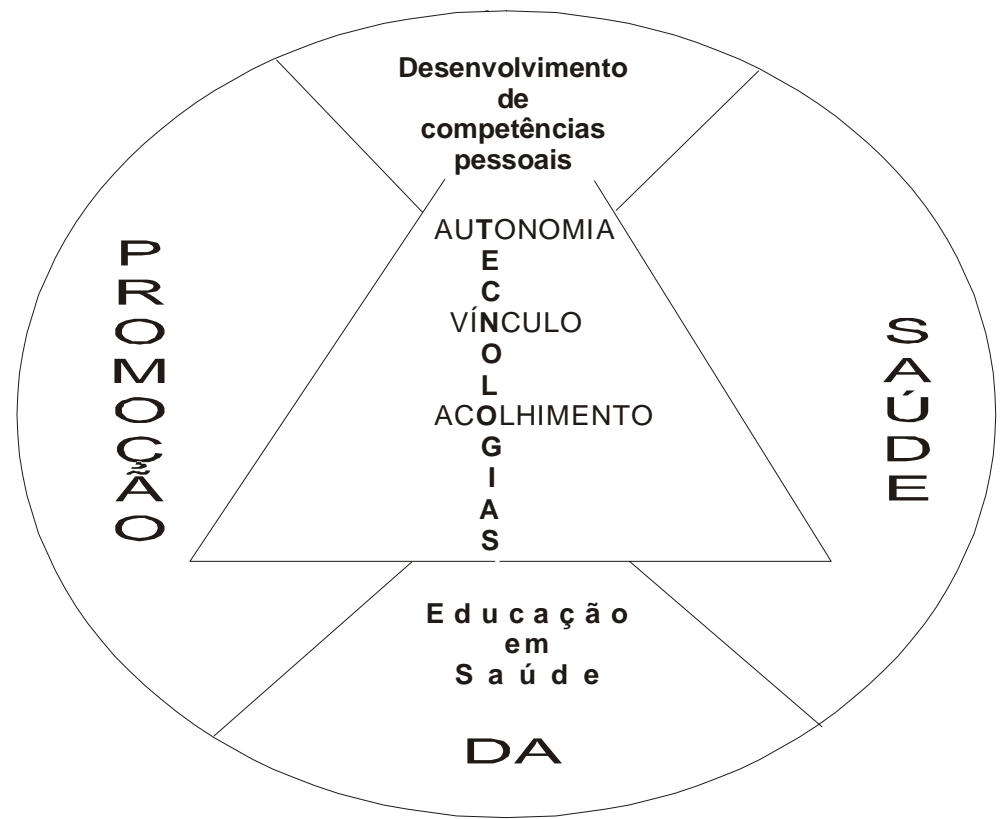

Figura 1. Esquema do referencial teórico para o cuidado em saúde na área de nefrologia.

focaliza mudanças de atitudes e motivação, demandando informação e orientação para lidar com a vida num ecossistema. Ambos centralizam as informações e orientações no conhecimento dos profissionais, e se caracterizam como autoritários, diretivos e prescritivos ${ }^{(10,11)}$. Este modo de atuar em saúde não tem se mostrado eficiente na melhoria da saúde da população.

O paradigma do "empowerment" difere dos anteriores em muitos aspectos. Esta palavra, do inglês, significa: conceder poder a...l autodeterminação/despertar da consciência, empoderamento. As ações de saúde não estão centradas unicamente no conhecimento dos profissionais da saúde, mas principalmente no conhecimento e nas experiências dos usuários. Esse paradigma é concebido como um processo de ação social que promove participação das pessoas no controle de suas vidas e de sua saúde e, portanto, suas estratégias são amplas e direcionadas para as mudanças sociais, individuais e políticas $^{(10)}$.

Essa visão de promoção da saúde está fundamentada nos documentos da $1^{\text {a }}$ Conferência Internacional sobre Promoção da Saúde realizada em Ottawa, Canadá (1986) e propõe mudança referente às políticas de saúde na direção da justiça social e da eqüidade como prérequisitos para a saúde ${ }^{(12)}$. Na mesma direção ideológica, outras conferências ocorreram: a Conferência de Adelaide (1988), de Sündsvall (1991) e de Jacarta (1997).

A Conferência de Otawa utiliza a combinação de distintos enfoques para melhorar a saúde, incluindo educação, informação, desenvolvimento e organização das comunidades e ações de defesa da saúde especificados nos seguintes critérios: a) a construção de políticas públicas saudáveis que abrange ações políticas em todos os setores governamentais ${ }^{(12)}$; b) a criação de ambientes favoráveis que exigem a criação de condições de trabalho e lazer seguras, satisfatórias e prazerosas ${ }^{(13)}$; c) o reforço da ação comunitária que tem como eixo impulsor o "empowerment", necessitando a criação de novos métodos de trabalho pelos profissionais da saúde, baseados em trabalhar "com" e "para" os usuários; d) o desenvolvimento de competências pessoais que apóia o desenvolvimento individual e comunitário mediante educação para a saúde, divulgação de informação e ajuda à população no desenvolvimento das competências para uma vida saudável; e) a reorientação dos serviços de saúde que propõe responsabilidade compartilhada entre os usuários, as associações e grupos comunitários, os profissionais da saúde e as pessoas com responsabilidade administrativa e governos, bem como o desenvolvimento da pesquisa em saúde, na renovação da educação da população e no ensino dos profissionais da saúde ${ }^{(12)}$.

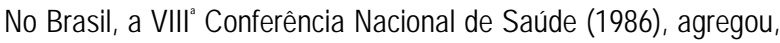
entre outros, o movimento da Reforma Sanitária e as idéias oriundas da Promoção à Saúde. A conferência foi propulsora do processo que viria estabelecer os princípios do Sistema Único de Saúde - SUS a serem garantidos pela Constituição Federal de 1988, tais como: a saúde como direito do cidadão e dever do Estado; a concepção ampliada de saúde; a participação popular; a universalidade do acesso; a integralidade das ações; a eqüidade na assistência; a descentralização política administrativa.

Portanto, devemos perceber o SUS não apenas como um direcionador da assistência prestada no âmbito coletivo, no lócus das unidades básicas de saúde, mas como um integrador da assistência prestada em todos os níveis do sistema, cabendo aos profissionais enfermeiros de nefrologia o entendimento dos princípios e organização do SUS, possibilitando a integralidade das ações em todos os graus da rede de atenção, incluindo o cuidado nas unidades de diálise. Acreditamos que as enfermeiras e enfermeiros de nefrologia poderão contribuir para que estes princípios possam ser viabilizados. Todavia, a maior responsabilidade da enfermagem de nefrologia no cuidado direto aos usuários será no desenvolvimento de competências pessoais e, para isso, propomos o desenvolvimento de tecnologias leves pela educação em saúde.

A educação em saúde é um dos principais componentes da promoção da saúde. Em primeira instância, é preciso que as enfermeiras e enfermeiros de nefrologia aproveitem o tempo durante o cuidado, por mais curto que seja, para se envolverem com a educação em saúde, de modo a criar um espaço de interação entre os profissionais e os usuários. No paradigma da promoção da saúde, educar implica na busca de uma formação teórica e prática dos profissionais da saúde, que possibilite a compreensão da realidade cotidiana dos usuários, ou seja, uma compreensão do ser humano em todas as suas dimensões e não apenas na dimensão biológica, como tem sido na maioria dos cursos profissionais na área da saúde. 
Se 0 cuidado for desenvolvido num espaço dialógico, o usuário compreenderá melhor sua vulnerabilidade determinada por condições cognitivas, comportamentais e sociais a certas doenças, e se sentirá responsável pelo cuidado de si. Esta forma de cuidar deixa de ser uma "ladainha" de ordens, do que pode e não pode fazer, "rezada" pelos profissionais; ao contrário, desenvolve, com o usuário, o poder para tomar decisões referentes à melhoria da própria vida. 0 diálogo configura o centro da postura profissional e acrescenta que o profissional da saúde precisa aprender a ouvir e, embora não conheça certas crenças da população, deverá respeitá-las ${ }^{(14)}$. Por outro lado, este precisa dizer 0 que sabe a respeito e criticar atitudes comprovadamente prejudiciais à saúde.

As condições crônicas requerem estratégias de cuidado especiais que ajudem os usuários a despertar a consciência para 0 autogerenciamento. Neste caso o tratamento médico é necessário, mas não se mostra suficiente para obter bons resultados, os usuários precisam participar do cuidado de forma ativa, bem como aprender a interagir entre si e com as organizações de saúde, e os profissionais devem proporcionar oportunidades para este aprendizado.

As instituições de saúde estão estruturadas para atendimento a usuários com problemas agudos e, por isso, os usuários em condições crônicas são atendidos quando apresentam episódios agudos provenientes de sua situação, ou então, são atendidos nas Unidades Básicas de Saúde, reunidos por grupos homogêneos (hipertensos, diabéticos, e outros) em grande número, onde os profissionais administram palestras sobre fatores de risco e estilo de vida. Em algumas instituições, a forma de agregação para atividades coletivas condiciona a presença do usuário ao recebimento da medicação gratuita a que tem direito.

Tratando-se de diabetes, o autogerenciamento é o grande desafio, pois envolve uma reorganização severa nas maneiras de levar a vida cotidiana, que deverá incluir um constante autocontrole dos níveis de glicose no sangue, dietas alimentares, atividades físicas diárias, medicação, cuidados especiais com os pés entre outros. Há necessidade de estabelecer um forte vínculo entre os profissionais da saúde e 0 usuário e seus familiares. Para que isso ocorra, torna-se imprescindível à construção de um espaço de relações de tal forma que os usuários se sintam confortáveis e tenham oportunidade de falar para alguém disposto a ouvi-los.

Os profissionais da saúde, para cuidar de usuários em condições crônicas precisam de novos modelos que ajudem a desenvolver competências avançadas de comunicação e de educação popular ${ }^{(15)}$.

O modo impessoal e descompromissado com que vem se conduzindo o trabalho em saúde tem inspirado profissionais da área da saúde a desenvolverem modelos mais condizentes com a situação humana dos usuários. Entre estes profissionais, Emerson Elias Merhy propõe modificar o modo de operar o trabalho cotidiano nos serviços de saúde, de maneira a construir um processo de trabalho que se expresse na mútua cumplicidade entre usuários e profissionais em prol da defesa à vida. Para isso, Merhy ${ }^{(16)}$ aposta no desenvolvimento de tecnologias e

${ }^{a}$ Merhy aponta o termo interseçores como um "inter, interventor, designando o que se produz na relação entre sujeitos".

\section{REFERÊNCIAS}

1. Murussi M, Coester A, Gross JL, Silveiro SP. Nefropatia diabética no diabete mellito tipo 2: fatores de risco e prevenção. Arq Bras Endocrinol Metab 2003 jun; 47(3):207-19.

2. Susser M, Suser E. Choosing a future for epidemiology II: From black box to chinese boxes and eco-epidemiology. Am J Public Health 1996 may; 86(5):674-77. as classifica em: tecnologias duras, que são representadas pelos equipamentos tecnológicos, tecnologias leve-duras, pelos saberes estruturados e tecnologias leves, que consistem na produção de relações interseçoras $^{\mathrm{a}(3)}$. As tecnologias leves estão centradas nos nossos conhecimentos de como trabalhar a relação de cidadania entre o usuário e o serviço, o usuário e o trabalhador e as atividades de grupos de gestão... estas tecnologias estão muito mais em nossas sabedorias, experiências, atitudes, compromissos, responsabilidades do que em equipamentos, espaços físicos, apesar de dependerem destes de alguma maneira, mas secundariamente ${ }^{(16)}$.

As tecnologias leves, produtoras de "bens relações", se desenvolvem pelo processo do trabalho vivo em ato. Desta forma, o termo tecnologia, neste trabalho, é entendido como sendo uma temática do trabalho na saúde como ação intencional para produção de bens, não necessariamente materiais, mas de bens simbólicos ${ }^{(16)}$. A ação intencional realiza-se em processo de trabalho vivo em ato, o qual implica em alguns instrumentos predominantemente educativos para produzir com os usuários e profissionais uma natureza modificada desse trabalho vivo. É no trabalho cotidiano em contato com o usuário, que se expressam alguns componentes vitais da tecnologia leve do trabalho em saúde.

As tecnologias articuladas à produção dos processos das relações se configuram por meio de práticas de acolhimento, vínculo e autonomização. $\mathrm{O}$ acolhimento consiste "na relação humanizada, acolhedora que os trabalhadores e o serviço...têm que estabelecer com os diferentes tipos de usuários que a eles aportam" (17). Portanto a criação de vínculos implica relações tão próximas e tão claras que reflita na sensibilização com o sofrimento do outro, fazendo com o profissional se torne referência.

\section{COMENTÁRIOS}

Como vemos, a busca de uma outra postura no cuidado à saúde dos usuários alicerçada na relação solidária entre os profissionais e usuários consiste em novos desafios também na área de nefrologia. Acreditamos que estes desafios podem ser enfrentados pelas tecnologias leves construídas pela educação em saúde com foco no usuário/cidadão. A educação em saúde poderá ocorrer de forma individual e ou de forma coletiva; em qualquer uma destas formas, o centro será o usuário, de maneira a se sentir partícipe do processo. A participação é um exercício democrático e implica em manter um diálogo entre os profissionais e os usuários. Os sujeitos dialógicos conversam e defendem sua identidade; desse modo, crescem com as experiências compartilhadas ${ }^{(18)}$. Pela educação em saúde, que consiste no trabalho vivo em ato, os profissionais de nefrologia poderão desenvolver espaços apropriados às relações sociais que se produzem no encontro com os usuários. Portanto, o espaço de relações é um lugar de vozes e escutas no trabalho vivo em ato, ou seja, encontro de pessoas que se colocam como instituinte e que querem falar e serem ouvidas em suas necessidades $^{(19)}$. É nesse espaço do trabalho vivo em ato com o usuário que se expressam alguns componentes vitais da tecnologia leve e, portanto, constitui espaço propício para o desenvolvimento de competências pessoais. Por fim, cabe a reflexão direcionada aos cursos de especialização em enfermagem de nefrologia para que incluam, no processo de formação, a visão ampla do cuidado, a exemplo do referencial proposto neste artigo e não a restringir apenas a técnicas de diálise e seus contornos limitados às unidades de diálises.

3. Novaes RT. Do biológico e do social. Um pequeno balanço. In: Fleury S, organizadora. Saúde e democracia : a luta do CEBES. São Paulo: Lemos Editorial; 1997. [s.p.].

4. Fonseca RMGS, Bertolozzi MR, Silva IA. O Uso da Epidemiologia na Enfermagem da Saúde Coletiva. Brasília (DF): ABEn; 1997. (Série didática: enfermagem no SUS). 
5. Costa DC. Epidemiologia-teoria e objeto. $3^{\mathrm{a}}$ ed. São Paulo (SP): Hucitec-Abrasco; 2002.

6. Testa M. Pensar em saúde. Porto Alegre (RS): Artmed; 1992.

7. Lancaster J, Lancaster W. Concepts for advanced nursing practice; the nurse as a change agent. St. Louis (USA): The C.V. Mosby Company; 1982

8. Fleury S. Saúde e democracia : a luta do CEBES. São Paulo (SP): Lemos Editorial; 1997.

9. Waitsman J. Saúde, cultura e necessidades. In: Fleury S, organizadora. Saúde: coletiva? Questionando a onipotência do social. Rio de Janeiro (RJ): Relumé-Dumará; 1992, p.157-73.

10. Norton L. Health promotion and health education: what role should the nurse adopt in practice? J Advanc Nurs 1998; 28 (6):1268-75.

11. Sundeen SJ, Stuart GW, Rankin EAD, Coben SA. Nursing client interation: Implementing the nursing process. $5^{\text {th }}$ ed. St. Louis (USA): Mosby; 1994.

12. Ministério da Saúde (BR). Promoção da Saúde: Carta de Otawa, Declaração de Adelaide, Declaração de Sandswall, Declaração de Bogotá. Brasília (DF): Ministério da Saúde; 1996.

13. Ashton J. La promoción de la salud, um nuevo concepto para uma nueva sanidad. Generalitat Valenciana. IVESP;1987.
14. Vasconcelos EM. Educação popular nos serviços de saúde. $3^{\mathrm{a}} \mathrm{ed}$. São Paulo (SP): Hucitec; 1997.

15. Organização Mundial da Saúde. Cuidados inovadores para condições crônicas: componentes estruturais de ação. Relatório mundial/ Organização Mundial da Saúde. Brasília (DF): OMS; 2003.

16. Merhy EE. Em busca de ferramentas analisadoras das tecnologias em saúde: a informação e o dia a dia de um serviço interrogando e gerindo trabalho em saúde. In: Merhy EE, Onoko R. Praxis en salud un desafio para lo público. São Paulo (SP): Hucitec; 1997. [s.p.].

17. Merhy EE. Em busca da qualidade dos serviços de saúde: os serviços de porta aberta para a saúde e o modelo técnico-assistencial em defesa da vida (ou como aproveitar os ruídos do cotidiano dos serviços de saúde e colegiadamente reorganizar o processo de trabalho na busca da qualidade das ações de saúde). In: Cecílio LCO, organizador. Inventando a mudança na saúde. $2^{\mathrm{a}}$ ed. São Paulo (SP): Hucitec; 1997. p.117-60.

18. Freire P. Pedagogia da esperança: um reencontro com a pedagogia do oprimido. $3^{\mathrm{a}}$ ed. Rio de Janeiro (RJ): Paz e Terra; 1992.

19. Merhy EE. O SUS e um dos seus dilemas: mudar a gestão e a lógica do processo de trabalho em saúde (Um ensaio sobre a micropolítica do trabalho vivo). In: Fleury S. Saúde e Democracia: a luta do CEBES. São Paulo (SP): Lemos Editorial; 1997. p. 125-41. 